\title{
Article \\ The Pattern of Hemoglobin A1C Trajectories and Risk of Herpes Zoster Infection: A Follow-Up Study
}

\author{
Bo-Lin Pan ${ }^{1}$, Chia-Pei Chou ${ }^{1}$, Kun-Siang Huang ${ }^{1}$, Pin-Jie Bin ${ }^{1}$, Kuei-Hau Luo ${ }^{2}$ and Hung-Yi Chuang ${ }^{3,4, *(1)}$ \\ 1 Department of Family Medicine, Kaohsiung Chang Gung Memorial Hospital, Kaohsiung 83301, Taiwan; \\ samohtte@cgmh.org.tw (B.-L.P.); libra760924@cgmh.org.tw (C.-P.C.); b9402019@cgmh.org.tw (K.-S.H.); \\ u107575105@kmu.edu.tw (P.-J.B.) \\ 2 Graduate Institute of Medicine, College of Medicine, Kaohsiung Medical University, \\ Kaohsiung 80708, Taiwan; u107800007@kmu.edu.tw \\ 3 Department of Community Medicine, Kaohsiung Medical University Hospital, Kaohsiung 80756, Taiwan \\ 4 Ph.D. Program in Environmental and Occupational Medicine, Research Center for Environmental Medicine, \\ Department of Public Health and Environmental Medicine, College of Medicine, Kaohsiung Medical University, \\ Kaohsiung 80708, Taiwan \\ * Correspondence: ericch@kmu.edu.tw
}

check for

updates

Citation: Pan, B.-L.; Chou, C.-P.; Huang, K.-S.; Bin, P.-J.; Luo, K.-H.; Chuang, H.-Y. The Pattern of Hemoglobin A1C Trajectories and Risk of Herpes Zoster Infection: A Follow-Up Study. Int. J. Environ. Res. Public Health 2022, 19, 2646. https://doi.org/10.3390/ ijerph19052646

Academic Editor: Fabrizio Bert

Received: 20 January 2022

Accepted: 22 February 2022

Published: 24 February 2022

Publisher's Note: MDPI stays neutral with regard to jurisdictional claims in published maps and institutional affiliations.

Copyright: (C) 2022 by the authors. Licensee MDPI, Basel, Switzerland. This article is an open access article distributed under the terms and conditions of the Creative Commons Attribution (CC BY) license (https:// creativecommons.org/licenses/by/ $4.0 /)$.

\begin{abstract}
To investigate the risks of herpes zoster (HZ) infection among heterogeneous $\mathrm{HbA1C}$ trajectories of patients with newly diagnosed type 2 diabetes, this cohort study used data from the Chang Gung Research Database (CGRD), from the 10-year period of 1 January 2007 to 31 December 2017. We applied group-based trajectory modeling (GBTM) to identify the patterns of $\mathrm{HbA1C}$ trajectories, and multiple Cox proportional hazards regressions were used to estimate the hazard ratio (HR) for the risk of HZ infection with adjustment of age, sex, and comorbidities. This study enrolled 121,999 subjects to perform the analysis. The GBTM identified four HbA1C trajectories: 'good control' (58.4\%), 'high decreasing' (8.9\%), 'moderate control' (25.1\%), and 'poor control' (7.6\%) with the mean HbA1C of $6.7 \%$ (50 mmol $/ \mathrm{mol}), 7.9 \%$ (63 mmol $/ \mathrm{mol}), 8.4 \%$ (68 mmol $/ \mathrm{mol})$, and 10.7\% (93 mmol $/ \mathrm{mol}$ ) respectively. The risk of HZ was significantly higher in the poor control with an HR $=1.44$ (95\% CI 1.26-1.64) after adjustment for confounders and comorbidities. The risk of HZ infection for the high decreasing group (initially poor then rapidly reaching optimal control) was nonsignificant compared to the good control group. In conclusion, the patients with poor glycemic control (mean $\mathrm{HbA1C}=10.7 \%$ ) had the highest risk of $\mathrm{HZ}$ infection. The patients with initial hyperglycemia then reaching optimal control could have a lower risk of $\mathrm{HZ}$ infection.
\end{abstract}

Keywords: type 2 diabetes mellitus; herpes zoster; glycated hemoglobin; group-based trajectory model (GBTM)

\section{Introduction}

Herpes zoster (HZ) is a viral infection, characterized by painful, unilateral vesicular skin rash. HZ usually occurs after primary varicella infection because of reactivation of latent varicella zoster virus (VZV) which results from lower VZV-specific cell-mediated immunity [1]. HZ can contribute to several complications, such as postherpetic neuralgia (PHN) and herpes zoster ophthalmicus. Both the skin rash and complications could disturb daily activity and sleep and impair the quality of life and working performance [1]. More than 1 million individuals in the United States were diagnosed with HZ annually. It is estimated that the lifetime risk of $\mathrm{HZ}$ infection is approximately $30 \%$. The incidence rate is 3 to 4 cases per 1000 person-years [1,2]. In Taiwan, the incidence rate is 3.62 to 4.89 cases per 1000 person-years in the general population and increases with older age according to the studies by using National Health Insurance Research Database (NHIRD) [3,4].

The risk of $\mathrm{HZ}$ infection depends on the immune status of the host, especially reduced T-cell-mediated immunity. Several immunocompromising diseases or medical conditions 
are the risk factors of HZ because of impaired T-cell immunity, such as malignancy, human immunodeficiency virus (HIV) disease, lymphoma, autoimmune disease, or persons receiving immunosuppressive therapy [5-7]. Patients with diabetes mellitus (DM) also have impaired cell-mediated cell immunity, which may result in a higher risk of infectious disease [8]. Previous studies have reported the association between HZ infection and diabetes [9-12], but the range of risk varied widely in the population of DM [13]. However, there are fewer studies to investigate the risk of $\mathrm{HZ}$ with uncontrolled diabetes compared to the controlled group. A nested case-control study in Israel reported the association between glycemic control and the incidence of $\mathrm{HZ}$. In the population under 45 years old, the risk of $\mathrm{HZ}$ increased with a high level $(>8 \%$ or $>64 \mathrm{mmol} / \mathrm{mol})$ of glycated hemoglobin $(\mathrm{HbA} 1 \mathrm{C})$ compared to the group with a low $\mathrm{HbA} 1 \mathrm{C}$ level $(<5 \%$ or $<31 \mathrm{mmol} / \mathrm{mol})$. However, this trend was not similar in older age [10].

Therefore, we used a large hospital-based cohort database in Taiwan with repeated and serial measurements of $\mathrm{HbA} 1 \mathrm{C}$ to perform trajectory analysis in the type $2 \mathrm{DM}$ patients. This study aimed to investigate the risk of $\mathrm{HZ}$ infection among the glycemic control that was differentiated by the distinct trajectories of $\mathrm{HbA} 1 \mathrm{C}$ by using group-based trajectory modeling.

\section{Materials and Methods}

The Chang Gung Research Database (CGRD) is a large deidentified database in Taiwan. The database originates from the electronic medical records (EMRs) of Chang Gung Memorial Hospital (CGMH), which is the largest hospital system in Taiwan. There are seven medical hospitals, including medical centers, regional hospitals, and district hospitals, which have a total of 10,070 beds and more than 280,000 patients hospitalized annually [14] All hospitals of this system use standardized and integrated EMRs including inpatient and outpatient visits, emergency department data, laboratory data, pathological reports, nursing records, disease category data, and operation reports [14,15]. The clinical diagnoses were identified by reading the International Classification of Diseases, 9th revision (ICD-9), and ICD-10 codes. The present study was approved by the Institutional Review Board of Chang Gung Memorial Hospital (approval number: 201801148B0D001). The Institutional Review Board waived the need for informed consent because all data were deidentified and anonymous.

\subsection{Study Design and Population}

The subjects who were diagnosed with diabetes mellitus were enrolled for the period of 1 January 2007 to 31 December $2017(n=397,993)$. The diabetes mellitus was confirmed by searching the ICD code (ICD-9: 250, ICD-10: E11) with at least three outpatient visits or one inpatient admission $(n=348,498)$. The date when the DM was confirmed was the index date. We extracted the laboratory data of $\mathrm{HbA} 1 \mathrm{C}$ in the first 2 years after the index date. We excluded the subjects less than 20 years of age. Because of the possible impaired immune function, the subjects with cancer history (ICD-9: 140-208, ICD-10 C00-C96), HIV infection (ICD-9: 042, 079.53, V08; ICD-10: B20, B97.35, Z21), type 1 DM (ICD-9: 250.x1, 250.x3), systemic lupus erythematosus (SLE) (ICD-9: 710, ICD-10: M32), or rheumatoid arthritis (RA) (ICD-9: 714, ICD-10: M05, M06) were excluded. The subjects who had HZ before the index date or nearly the index date was also excluded. The live-attenuated VZV vaccine was released in 2013 in Taiwan. The vaccine was expensive in Taiwan; thus, 116 patients who had taken that vaccine were also excluded. Because the processing of the HbA1C trajectory needs at least 3 measurements of $\mathrm{HbA1C}$, we excluded the subjects with less than $3 \mathrm{HbA1C}$ measurements during the first 2 years. Finally, a total of 121,999 eligible subjects were enrolled for analysis. A flowchart of the study design and patients is shown in Figure 1. 


\section{7,993 subjects}

with ICD-9: 250 or ICD-10: E11 from 1 Jan. 2007 to 31 Dec. 2017

Exclude $<3$ outpatient records: 49,495

\section{8,498 subjects confirmed DM}

Exclusion Comorbidity:

- Cancer: 63,792

- HIV: 173

- Type 1 DM: 10,891

- SLE: 2818

RA: 2626

\section{Exclusion Criteria:}

- Age < 20 years: 674

- $\mathrm{HZ}$ before index date of DM: 1581

- $\mathrm{HbA} 1 \mathrm{C}<3$ times in first 2 years: 142,373

- $\mathrm{HZ}$ occurred after index date $<1$ year: 838

- Zoster vaccine injection: 116

- Incorrect data of age and sex: 617

\section{1,999 eligible subjects}

Figure 1. Flowchart of study design and patients.

\subsection{Glycated Hemoglobin Level}

The series of $\mathrm{HbA} 1 \mathrm{C}$ within the first 2 years after the index date were extracted. In Taiwan, the recommended testing interval of $\mathrm{HbA} 1 \mathrm{C}$ was every 3 months according to the clinical practice guideline for diabetes care published by the Diabetes Association of Taiwan [16]. The interval between each measurement should be at least 3 months; thus, we excluded the subjects with less than $3 \mathrm{HbA} 1 \mathrm{C}$ measurements during the first 2 years. Then, the processing of the $\mathrm{HbA} 1 \mathrm{C}$ trajectory to identify the district glycemic pattern was performed. Besides, the last measurements of $\mathrm{HbA} 1 \mathrm{C}$ in one year before zoster infection were collected and compared with the data in the first 2 years after the index date.

\subsection{Outcome}

The outcome of this cohort study was the new occurrence of HZ. The newly diagnosed HZ was identified by searching the ICD code (ICD-9: 053; ICD-10: B02, G53.0) which appeared the first time during the follow-up period, based on the outpatient, inpatient, and emergency department data. The subjects who had HZ before the index date of DM or HZ occurrence within 1 year after the index date were excluded. All subjects were followed until death or HZ infection until 31 December 2017.

\subsection{Major Comorbidities}

Comorbidities were identified before the index date as confounders, including hypertension (ICD-9: 40, ICD-10: I10), chronic obstructive pulmonary disease (COPD) (ICD-9: 490-491, ICD-10: J44), heart failure (ICD-9: 428, ICD-10: I50), ischemic heart disease (ICD-9: 410-414, ICD-10: I20-I25), stroke (CD-9: 433-434, ICD-10: I63, I64), and chronic kidney 
disease (ICD-9: 585, ICD-10: N18). The comorbidities were confirmed by at least three outpatient visits or one admission or emergency visit.

\subsection{Statistical Analysis}

We applied group-based trajectory modeling (GBTM) to identify the HbA1C trajectories. A similar developmental curve over time was recognized and classified into a subgroup $[17,18]$. The optimal number of subgroups should be determined. The Bayes information criterion (BIC) was used to evaluate the likelihood of the model and the number of subgroups in the model. A lower BIC value showed a better fit with the number of groups. Besides, each group needed to contain $>5 \%$ population. The average posterior probabilities of group membership were calculated for each group and should be larger than 0.7.

We used the chi-square tests (categorical variables) and one-way ANOVA (continuous variables) to examine the differences among these subgroups. Multiple Cox proportional hazards regression was applied to estimate the hazard ratio (HR) for HZ infection risk of each $\mathrm{HbA} 1 \mathrm{C}$ trajectory with adjustment of confounding factors, including age, gender, and comorbidity. The gender and age were adjusted in model 1, and comorbidities were added as confounders in model 2 . Since the $\mathrm{HbA} 1 \mathrm{C}$ trajectory pattern of the first 2 years was used to define subgroup, we tested the last year's $\mathrm{HbA} 1 \mathrm{C}$ before $\mathrm{HZ}$ infection using one-way ANOVA to compare these subgroups; once AVOVA was significant, then the post hoc test by Scheffe's method was used to check the different $\mathrm{HbA} 1 \mathrm{C}$ values for every other group in the four groups.

All statistical tests were two-sided and were significant if $p<0.05$. We used SAS 9.4 (SAS Institute Inc., Cary, CA, USA) for statistical analysis and installed the PROC TRAJ application to perform the trajectory analysis $[17,19,20]$.

\section{Results}

The trajectories of $\mathrm{HbA} 1 \mathrm{C}$ during the first 2 years after the index date are shown in Figure 2. The series of $\mathrm{HbA} 1 \mathrm{C}$ was processed by GBTM. The BIC became lower gradually from group 2 to group 4 with cubic order (1289537, 1246499, and 1208534, respectively). Although the addition of a fifth group has the lowest BIC (1190933), the sample size of the smallest group was below 5\% (Figure 2).

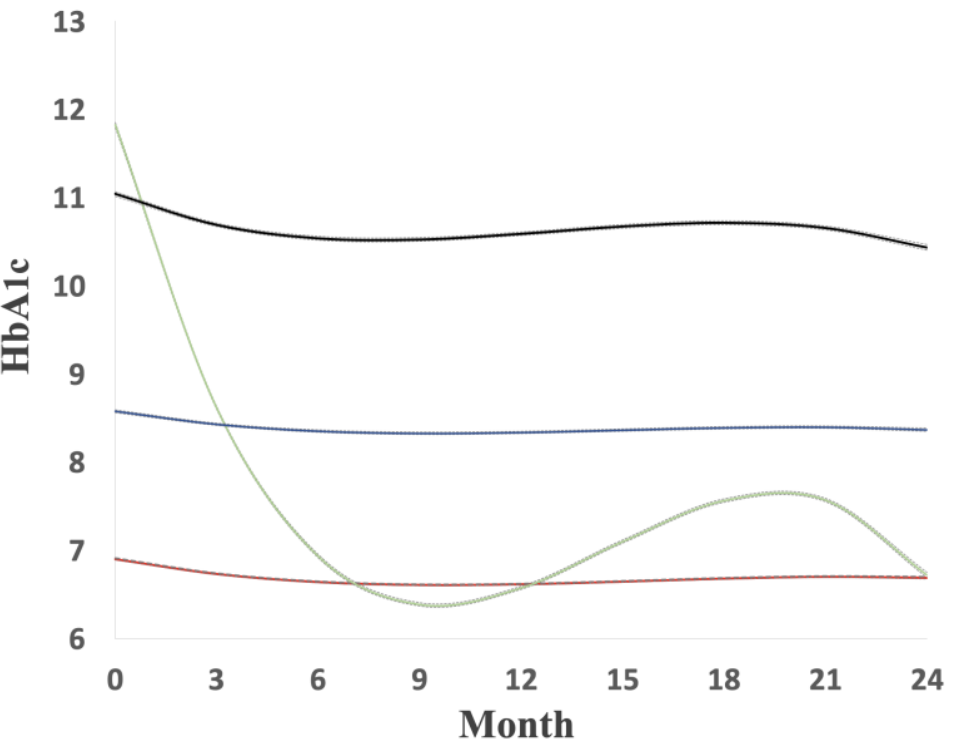

Figure 2. Trajectories (99\% CIs) of $\mathrm{HbA}_{1} \mathrm{C}$ within first 2 years after index date: red line means good control group ( $58.4 \%$ of the population); green line means high decreasing ( $8.9 \%$ of the population); blue line means moderate stable ( $25.1 \%$ of the population); black line means poor control $(7.6 \%$ of the population) (dot line means $99 \%$ confidence interval). 
Therefore, the best fit of this model was four groups with cubic orders. The largest group, with $58.4 \%$ of the patients, showed a stable pattern of good glycemic control (HbA1C $6.6-6.9 \%$ or $49-52 \mathrm{mmol} / \mathrm{mol}$ ) and was named the 'good control' group. The second group, with $8.9 \%$ of the patients, initially showed high glycemic control during the first year but subsequently improved during follow-up (HbA1C $6.4-11.8 \%$ or $46-105 \mathrm{mmol} / \mathrm{mol}$ ) and was named the 'high decreasing' group. The third group, with $25.1 \%$ of the patients, showed a stable pattern of moderate glycemic control (HbA1C $8.3-8.6 \%$ or $67-70 \mathrm{mmol} / \mathrm{mol}$ ) and was named the 'moderate stable' group. The fourth group, with $7.6 \%$ of the patients, showed a stable pattern of hyperglycemia (HbA1C $10.4-11.0 \%$ or $90-97 \mathrm{mmol} / \mathrm{mol}$ ) and was named the 'poor control' group (Figure 2).

This study enrolled 121,999 patients finally. The baseline characteristics of patients are described in Table 1. The mean age (standard deviation (SD)) was 60.4 (12.6) years and a male preponderance of $53.7 \%$. The median (interquartile range (IQR)) follow-up period was 6.1 (3.2-9.8) years. The mean $\mathrm{HbA} 1 \mathrm{C}$ within 2 years was $7.58 \%(59 \mathrm{mmol} / \mathrm{mol})$. The average incidence of HZ from 2007 to 2017 was estimated at 3.8 cases per 1000 person-years. The patients in the 2nd to 4 th groups were more likely younger and had longer follow duration compared to the good control group. The means of $\mathrm{HbA1C}$ within 2 years of 'good control', 'high decreasing', 'moderate stable', and 'poor control' groups were $6.7 \%$ (50 mmol $/ \mathrm{mol}), 7.9 \%(63 \mathrm{mmol} / \mathrm{mol}), 8.4 \%(68 \mathrm{mmol} / \mathrm{mol})$, and $10.7 \%(93 \mathrm{mmol} / \mathrm{mol})$ respectively. The proportion of patients with comorbidities at baseline was higher among the patients in the good control group, compared with the other 3 groups (Table 1).

Table 1. Baseline character by the groups with $\mathrm{HbA}_{1} \mathrm{C}$ trajectories.

\begin{tabular}{|c|c|c|c|c|c|c|c|c|c|c|c|}
\hline & \multicolumn{2}{|c|}{ All } & \multicolumn{2}{|c|}{$\begin{array}{c}\text { Group } 1 \\
\text { Good Control }\end{array}$} & \multicolumn{2}{|c|}{$\begin{array}{c}\text { Group } 2 \\
\text { High Decreasing }\end{array}$} & \multicolumn{2}{|c|}{$\begin{array}{c}\text { Group } 3 \\
\text { Moderate Stable }\end{array}$} & \multicolumn{2}{|c|}{$\begin{array}{c}\text { Group } 4 \\
\text { Poor Control }\end{array}$} & $p$ Value \\
\hline Total enrollee $n .(\%)$ & \multicolumn{2}{|c|}{121,999} & \multicolumn{2}{|c|}{$71,296(58.4)$} & \multicolumn{2}{|c|}{$10,888(8.9)$} & \multicolumn{2}{|c|}{$30,602(25.1)$} & \multicolumn{2}{|c|}{$9213(7.6)$} & \\
\hline Herpes Zoster $n .(\%)$ & 2867 & $(2.4)$ & 1621 & $(2.3)$ & 183 & $(1.7)$ & 794 & $(2.6)$ & 269 & $(2.9)$ & $<0.0001$ \\
\hline Age, years, mean (SD) & 60.4 & $(12.6)$ & 62.1 & (12.4) & 56.1 & $(12.7)$ & 59.6 & $(12.1)$ & 55.6 & $(12.6)$ & $<0.0001$ \\
\hline Sex, $n .(\%)$ & & & & & & & & & & & $<0.0001$ \\
\hline Male & 65,490 & $(53.7)$ & 38,046 & $(53.4)$ & 6659 & $(61.2)$ & 16,000 & $(52.3)$ & 4785 & $(52.0)$ & \\
\hline Female & 56,509 & $(46.3)$ & 33,250 & $(46.6)$ & 4229 & (38.9) & 14,602 & $(47.7)$ & 4428 & $(48.1)$ & \\
\hline $\begin{array}{l}\text { Follow date, years, } \\
\text { median (IQR) }\end{array}$ & 6.1 & $(3.2-9.8)$ & 5.8 & $(3.0-9.4)$ & 5.1 & $(2.5-8.1)$ & 7.2 & (3.8-10.8) & 6.9 & $(3.4-10.5)$ & $<0.0001$ \\
\hline $\begin{array}{l}\text { Mean } \mathrm{HbA}_{1} \mathrm{C}, \% \text {, } \\
\text { mean }(\mathrm{SD})\end{array}$ & 7.58 & $(1.68)$ & 6.70 & $(0.79)$ & 7.93 & $(2.27)$ & 8.43 & $(1.17)$ & 10.69 & $(1.80)$ & $<0.0001$ \\
\hline Comorbidity, n. (\%) & & & & & & & & & & & \\
\hline Hypertension & 22,440 & $(18.4)$ & 17,973 & $(25.2)$ & 1359 & $(12.5)$ & 2654 & $(8.7)$ & 454 & $(4.9)$ & $<0.0001$ \\
\hline COPD & 2214 & $(1.8)$ & 1704 & $(2.4)$ & 154 & $(1.4)$ & 293 & $(1.0)$ & 63 & $(0.7)$ & $<0.0001$ \\
\hline Heart failure & 2701 & $(2.2)$ & 2030 & $(2.9)$ & 153 & $(1.4)$ & 419 & (1.4) & 99 & $(1.1)$ & $<0.0001$ \\
\hline Ischemic heart disease & 7382 & (6.1) & 5747 & $(8.1)$ & 382 & $(3.5)$ & 1052 & $(3.4)$ & 201 & $(2.2)$ & $<0.0001$ \\
\hline Stroke & 2958 & $(2.4)$ & 2344 & $(3.3)$ & 185 & (1.7) & 364 & $(1.2)$ & 65 & $(0.7)$ & $<0.0001$ \\
\hline $\begin{array}{l}\text { Chronic kidney } \\
\text { disease }\end{array}$ & 2206 & $(1.8)$ & 1676 & $(2.4)$ & 75 & $(0.7)$ & 373 & $(1.2)$ & 83 & $(0.9)$ & $<0.0001$ \\
\hline
\end{tabular}

COPD, chronic obstructive pulmonary disease; IQR, interquartile range; $\mathrm{SD}$, standard deviation.

During the follow-up period (median 6.1 years, IQR 3.2-9.8 years), a total of 2867 patients suffered from HZ, about $2.4 \%$ of this population. The Kaplan-Meier curves for zoster infection by $\mathrm{HbA} 1 \mathrm{C}$ trajectories are shown in Figure 3. The poor control groups had a higher proportion of zoster than the other groups $(\log$-rank $p=0.025)$. The high decreasing group tended to have the lowest incidence rate.

We used multiple Cox proportional hazards regression to estimate the hazard ratio of zoster for each $\mathrm{HbA1C}$ trajectories, as shown in Table 2. The risk of $\mathrm{HZ}$ was significantly higher in the poor control group after adjusting for age and gender (Model 1) with HR 1.41 and $95 \%$ confidence interval (CI) 1.23-1.60, and it was still significantly higher after adjusting for comorbidities (Model 2) (HR 1.44, 95\% CI 1.26-1.64). The other groups, the 'moderate stable' and the 'high decreasing' groups, were at higher risks, but the differences were statistically nonsignificant after adjusting for age, gender, and comorbidities. The risk 
of zoster was significantly higher in the poor control group than the other groups both in Model 1 and Model 2 analysis.

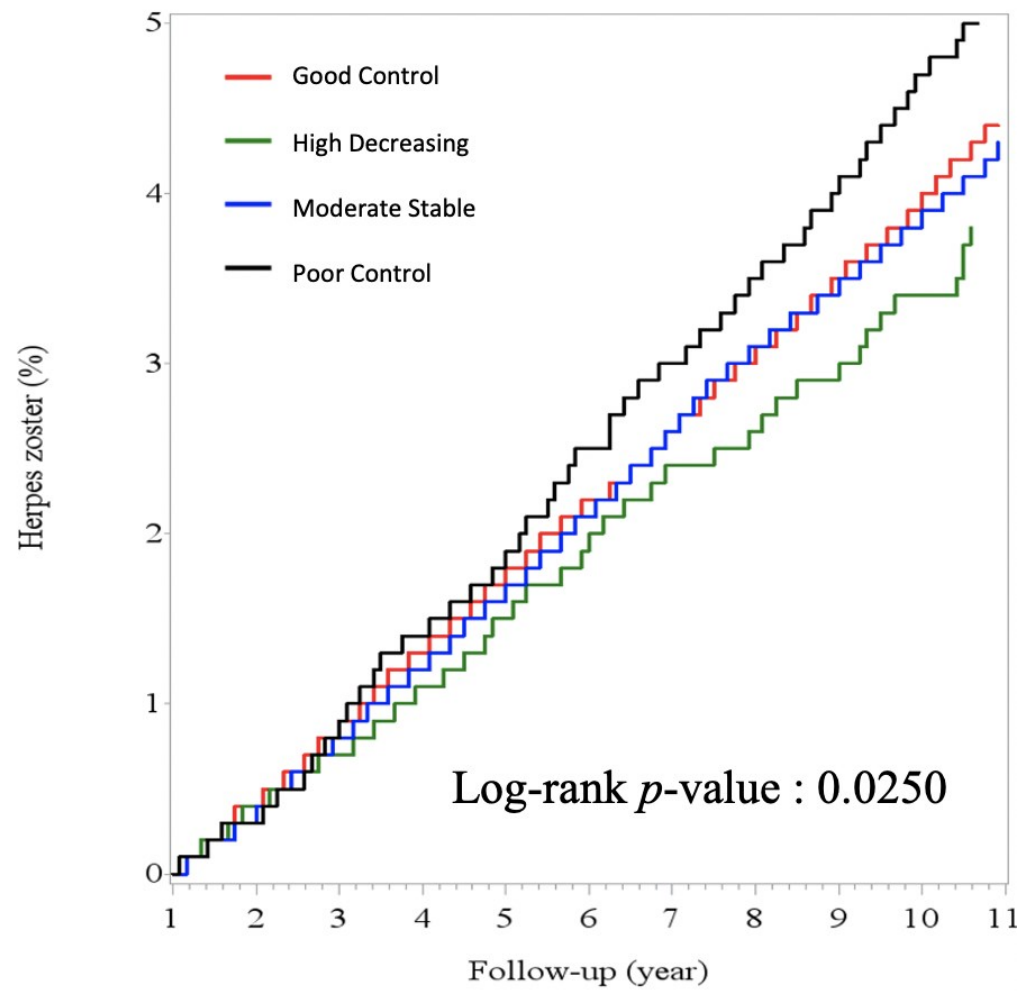

Figure 3. Kaplan-Meier curve for zoster infection by $\mathrm{HbA} 1 \mathrm{C}$ trajectories. The poor control group (black line) had a higher incidence rate than the other 3 groups (log-rank $p$-value: 0.0250).

Table 2. Cox regression models with $\mathrm{HbA}_{1} \mathrm{C}$ trajectories to estimate hazard ratio of zoster.

\begin{tabular}{|c|c|c|c|c|c|c|}
\hline \multirow{2}{*}{$\begin{array}{c}\text { Group } \\
\mathrm{HbA}_{1} \mathrm{C} \text { trajectories }\end{array}$} & \multicolumn{2}{|c|}{ Crude HR $(95 \% \mathrm{Cl})$} & \multicolumn{2}{|c|}{ Model $1^{\dagger}$ HR $(95 \%$ Cl) } & \multicolumn{2}{|c|}{ Model $2 \ddagger$ HR $(95 \% \mathrm{Cl})$} \\
\hline & & & & & & \\
\hline Group 1 good control & 1.00 & (reference) & 1.00 & (reference) & 1.00 & (reference) \\
\hline Group 2 high decreasing & 0.87 & $(0.74-1.01)$ & 1.04 & $(0.89-1.21)$ & 1.06 & $(0.90-1.23)$ \\
\hline Group 3 moderate stable & 0.98 & $(0.90-1.06)$ & 1.06 & $(0.97-1.15)$ & 1.08 & (0.99-1.18) \\
\hline Group 4 poor control & 1.15 & $(1.01-1.30)$ & 1.41 & $(1.23-1.60)$ & 1.44 & $(1.26-1.64)$ \\
\hline Age & 1.03 & $(1.03-1.04)$ & 1.03 & $(1.03-1.04)$ & 1.03 & $(1.03-1.04)$ \\
\hline \multicolumn{7}{|l|}{ Sex } \\
\hline Female & 1.00 & (reference) & 1.00 & (reference) & 1.00 & (reference) \\
\hline Male & 0.81 & $(0.75-0.87)$ & 0.91 & $(0.85-0.98)$ & 0.90 & $(0.83-0.97)$ \\
\hline Hypertension & 1.16 & $(1.05-1.29)$ & & & 1.01 & $(0.90-1.14)$ \\
\hline COPD & 1.94 & $(1.52-2.49)$ & & & 1.63 & $(1.26-2.09)$ \\
\hline Heart failure & 1.18 & $(0.89-1.56)$ & & & 0.89 & $(0.67-1.19)$ \\
\hline Ischemic heart disease & 1.26 & $(1.07-1.48)$ & & & 1.10 & $(0.92-1.31)$ \\
\hline Stroke & 1.37 & $(1.09-1.74)$ & & & 1.10 & $(0.86-1.40)$ \\
\hline Chronic kidney disease & 2.99 & $(2.42-3.68)$ & & & 2.80 & $(2.26-3.46)$ \\
\hline
\end{tabular}

HR, hazard ratio; CI, confidence interval; ${ }^{\dagger}$ Model 1: adjusted for sex and age; ${ }^{\ddagger}$ Model 2: model $1+$ adjusted for comorbidities.

The means of HbA1C in the last year before HZ infection were shown in Table 3. The patients with zoster infection had a similar trend compared with the first 2 years. The average $\mathrm{HbA1C}$ was highest in the poor control group (mean 9.73\%, SD 1.11) and lowest in the good control group (mean 6.77\%, SD 0.69\%). The one-way ANOVA analysis revealed a significant difference between the four groups. The post hoc tests with Scheffe's method showed each group was significantly different from the others. In other words, the four 
groups' order in the last year before HZ infection was the same as the trajectory groups in the first 2 years after the index date.

Table 3. The HbA1C in the last year before $\mathrm{HZ}$ infection.

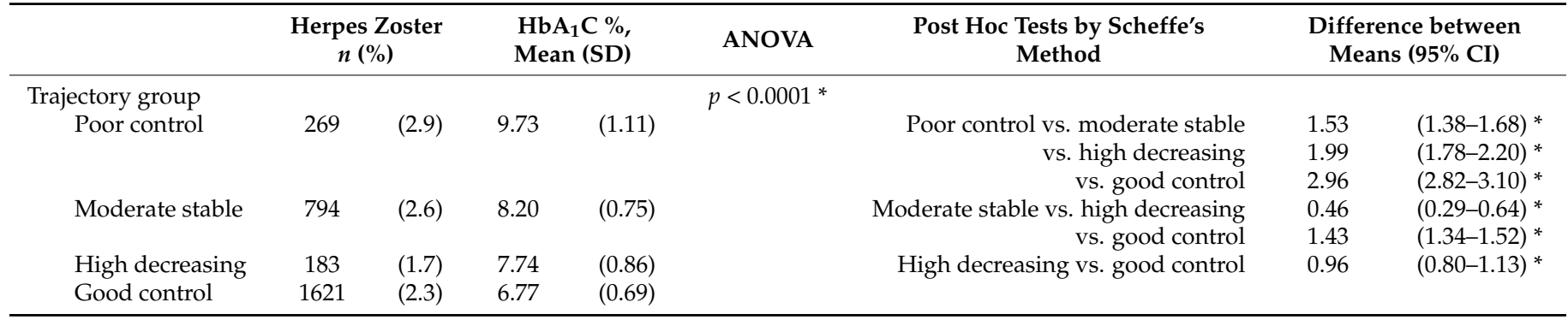

$\mathrm{CI}$, confidence interval; ${ }^{*} p$ value $<0.05$ indicates significant difference.

\section{Discussion}

In the present study, $58.4 \%$ of the patients maintained stable good glycemic control, and $8.9 \%$ of the patients were in the high decreasing trajectory group. Similar distinct $\mathrm{HbA} 1 \mathrm{C}$ trajectories were observed in the other studies [18,21]. A European study from the large Diabetes Patienten Verlaufsdokumentation (DPV) multicenter diabetes registry including 6355 subjects with a 5-year follow-up period showed the largest group (56\%) had persistent good control and $12 \%$ of the population showed high decreasing glycemic status in the cohort whereas $6 \%$ of the population had poor glycemic control [18]. Another study with a longer follow-up period based on Kaiser Permanente Northern California Diabetes Registry reported $82.5 \%$ of the patient had a 'low stable' HbA1C pattern [21]. Other trajectories, including 'moderate increasing late', 'high decreasing early', 'moderate peaking late', and 'moderate peaking early', accounted for $17.5 \%$. This distinct pattern was different from that of previous DPV studies and our results, which may be due to the longer follow-up period (10 years). In the first 5 years, the pattern of the trajectory was like our results [21].

The patients with poor glycemic control have a higher risk of $\mathrm{HZ}$ infection after adjusting for confounders and comorbidities. However, the patients with initially poor control in the first year and then reaching near-optimal glycemic control subsequently had a lower risk of $\mathrm{HZ}$ infection and had no statistical difference from the good control group. The results suggest that the patients with poor DM control have a higher risk of $\mathrm{HZ}$ infection, but the risk would be lower if the hyperglycemia became controlled and maintained within optimal levels.

Several studies reported the association between DM and HZ infection [9-12]. The cell-mediated immunity (CMI) may play a key role in suppressing the reactivation of the VZV. Among the patients with uncontrolled DM, hyperglycemia compromises the CMI, including the activation of phagocytes, memory CD4+ and cytotoxic CD8+ T cells, and a variety of cytokines [22,23]. A study that was designed to investigate T-cell responses to Streptococcus pneumoniae stimulation reported that lower frequency of total CD+ T cells and diminishing memory CD4+ T-cell response were associated with elevated blood glucose and glycated hemoglobin [24]. In addition, the phagocytosis dysfunction of monocytes was found among patients with chronic hyperglycemia [25]. The individuals with shortterm hyperglycemia had changes in the gene expression of cytokines and chemokines [26]. A study investigated the VZV-specific CMI which was measured by IFN- $r$ ELISPOT assay among patients with DM and found that the VZV-specific CMI was lower among the patients with DM compared with healthy participants. The results suggest a higher risk of $\mathrm{HZ}$ infection in patients with diabetes mellitus [27]. However, few studies explored dose-effect relationships such as those between blood sugar or $\mathrm{HbA} 1 \mathrm{C}$ levels and molecular reactions in CMI. Our finding would be a clue for further researches on increasing $\mathrm{HbA} 1 \mathrm{C}$ to disturb the molecular reactions in CMI. 
To our knowledge, the study was the first study to estimate the risk of HZ infection with a distinct pattern of glycemic control by using the trajectory model. Only a study in Israel using average $\mathrm{HbA} 1 \mathrm{C}$ investigated the impact of glycemic control on $\mathrm{HZ}$ infection. That study reported that younger patients ( $<45$ years) with worse glycemic control $(\mathrm{HbA} 1 \mathrm{C}>8 \%)$ had a higher risk of $\mathrm{HZ}$ infection compared with the patients with good glycemic control $(\mathrm{HbA} 1 \mathrm{C}<5 \%)$, but this finding was not seen in older age [10]. This finding was similar to ours. Another study used trajectories of $\mathrm{HbA} 1 \mathrm{C}$ and also divided them into four groups; however, the study did not analyze specific complications of DM. Furthermore, our study used this methodology to find the risk of HZ in DM patients and similarly found two smaller groups that exhibited either persistent poor $(7.6 \%)$ or initial poor $(8.9 \%)$ glycemic control and then rapidly improved during the first year, which had a statistically different result of $\mathrm{HZ}$ infection risk. The finding led us positively to treat and encourage the patients with initially poor glycemic control.

There are some strengths of our study. First, this CGRD dataset was so large that our study enrolled 122,068 subjects to be analyzed, containing younger and elder subjects. The overall outpatient and inpatient coverage rates of the CGRD were $21.2 \%$ and $12.4 \%$ in Taiwan. The DM-specific coverage was $29 \%$ in outpatients and $16 \%$ in inpatients, almost one-third in Taiwan [14]. According to a study based on NHIRD, the average incidence of HZ infection from 2005 to 2011 was estimated at 3.6 cases per 1000 person-years [4]. This incidence was similar to our study with an incidence rate of 3.8 cases per 1000 person-years from 2007 to 2017. This is the large real database using our ordinary clinical practice. Second, our longitudinal glycemic data were analyzed in distinct trajectories. Previous studies which investigated the association between glycemic control and outcomes have used the data of $\mathrm{HbA} 1 \mathrm{C}$ with single time or average $\mathrm{HbA} 1 \mathrm{C}$ in the period of follow-up, considering the difference of $\mathrm{HbA} 1 \mathrm{C}$ over time $[10,28,29]$. However, the character of glycemic control with $\mathrm{HbA} 1 \mathrm{C}$ data was heterogeneous and dynamic. These approaches which used "one size fits all" data could not represent the actual pattern of change over time. Our trajectory method to classify the distinct glycemic pattern may fit clinical practice better and more accurately.

There were several limitations in our study. Information bias could have happened where the actual time of newly diagnosed diabetes may be before the index date in this database. Because CGMH served often as a referral hospital for advanced care, patients might be initially diagnosed or be treated somewhere else and then receive treatment in our medical system. However, DM is a chronic proceeding disease, and it is difficult to confirm the definite date of DM onset. In addition, the study was a longitudinal follow-up study using series $\mathrm{HbA} 1 \mathrm{C}$, and the severity of $\mathrm{HZ}$ infection should drive patients to visit our medical system. Consequently, the information bias did not skew our results.

The selection bias was also noted. The patients without three $\mathrm{HbA} 1 \mathrm{C}$ measurements were excluded. These may include those who were without regular measurement but maintained good glycemic control because the medical exams may not be necessary. If this assumption is true, the results would be overestimated. However, Taiwan National Health Insurance strongly recommended checking $\mathrm{HbA} 1 \mathrm{C}$ for $\mathrm{DM}$ patients, and this check was linked to insurance payment; thus, the exclusion of these patients would not likely lead to selection bias.

Third, we used the series $\mathrm{HbA} 1 \mathrm{C}$ data for the first 2 years, not all values within the whole follow-up time. There were two reasons for this. The median (IQR) follow-up period of all subjects was 6.1 (3.2-9.8) years, and the cases with HZ infection had a shorter follow-up period (median 4.4, IQR 2.7-4.8). If we used the data for more years, the number of missing values of $\mathrm{HbA} 1 \mathrm{C}$ would greatly increase, and the trajectory of glycemic control would not be reliable. In addition, the $\mathrm{HZ}$ infection could worsen glycemic control [30]. The value of $\mathrm{HbA} 1 \mathrm{C}$ near the timing of $\mathrm{HZ}$ infection may be less reliable. Hence, we chose to analyze the first 2 years of $\mathrm{HbA} 1 \mathrm{C}$ data to reduce such error. Moreover, the order of $\mathrm{HbA} 1 \mathrm{C}$ levels among these four groups in the last year before $\mathrm{HZ}$ infection was similar to 
that in the first 2 years after the index date. This finding could prove that the HbA1C levels in each group were not changed much during the follow-up period.

\section{Conclusions}

In conclusion, the patients with poor glycemic control have a higher risk of $\mathrm{HZ}$ infection ( $\mathrm{HR}=1.44,95 \% \mathrm{CI}$ : 1.26-1.64). However, patients with initial poor glycemic control then becoming aggressively and subsequently controlled (the group of high decreasing $\mathrm{HbA1C}$ ) would have no significant risk of $\mathrm{HZ}$ infection compared to the group of good control. Therefore, the management of hyperglycemia should be administered as soon as possible, and the early achievement of good glycemic control would be better to avoid HZ infection. Consequently, medical expenses could be reasonably reduced, and quality of life would be improved.

Author Contributions: Conceptualization, B.-L.P. and H.-Y.C.; methodology, H.-Y.C.; software, K.-H.L.; validation, B.-L.P., C.-P.C. and H.-Y.C.; formal analysis, P.-J.B.; investigation, B.-L.P. and H.-Y.C.; resources, K.-S.H.; data curation, K.-S.H.; writing-original draft preparation, B.-L.P.; writing-review and editing, H.-Y.C.; visualization, P.-J.B.; supervision, H.-Y.C.; project administration, K.-H.L.; funding acquisition, B.-L.P. and H.-Y.C. All authors have read and agreed to the published version of the manuscript.

Funding: This work was supported by grants from Kaohsiung Chang Gung Memorial Hospital (CFRPG8H0331) and Kaohsiung Medical University Hospital (KMUH110-0T01) and partially by the Research Center for Environmental Medicine, Kaohsiung Medical University, Kaohsiung City, Taiwan, from The Featured Areas Research Center Program within the framework of the Higher Education Sprout Project by the Ministry of Education (MOE) in Taiwan and by Kaohsiung Medical University Research Center Grant (KMU-TC109A01-1).

Institutional Review Board Statement: The study was conducted according to the guidelines of the Declaration of Helsinki and approved by the Institutional Review Board of Chang Gung Memorial Hospital (approval number 201801148B0D001 and date of approval 07/23/2018).

Informed Consent Statement: The Institutional Review Board waived the need for informed consent because all data were deidentified and anonymous.

Data Availability Statement: The data could be applied to use via an application proceeding in Kaohsiung Chang Gung Memorial.

Acknowledgments: We appreciate the Biostatistics Center, Kaohsiung Chang Gung Memorial Hospital, for statistics work. We also wish to thank Yao-Hsu Yang for comments and assistance in performing the data analysis.

Conflicts of Interest: The authors declare no conflict of interest.

\section{References}

1. Cohen, J.I. Clinical practice: Herpes zoster. N. Engl. J. Med. 2013, 369, 255-263. [CrossRef] [PubMed]

2. Lee, S.M.; Han, J.; Yang, C.M.; Choi, C.Y.; Khoramnia, R.; Chung, T.-Y.; Lim, D.H. Chronic and recurrent herpes zoster ophthalmicus. Medicina 2021, 57, 999. [CrossRef] [PubMed]

3. Jih, J.S.; Chen, Y.J.; Lin, M.W.; Chen, Y.C.; Chen, T.J.; Huang, Y.L.; Chen, C.C.; Lee, D.D.; Chang, Y.T.; Wang, W.J.; et al. Epidemiological features and costs of herpes zoster in Taiwan: A national study 2000 to 2006. Acta Derm. Venereol. 2009, 89, 612-616. [CrossRef] [PubMed]

4. Ke, C.C.; Lai, H.C.; Lin, C.H.; Hung, C.J.; Chen, D.Y.; Sheu, W.H.; Lui, P.W. Increased risk of herpes zoster in diabetic patients comorbid with coronary artery disease and microvascular disorders: A population-based study in taiwan. PLoS ONE 2016, 11, e0146750. [CrossRef]

5. Hata, A.; Kuniyoshi, M.; Ohkusa, Y. Risk of Herpes zoster in patients with underlying diseases: A retrospective hospital-based cohort study. Infection 2011, 39, 537-544. [CrossRef]

6. Kennedy, P.G.E.; Gershon, A.A. Clinical features of varicella-zoster virus infection. Viruses 2018, 10, 609. [CrossRef]

7. Marra, F.; Parhar, K.; Huang, B.; Vadlamudi, N. Risk Factors for Herpes Zoster Infection: A Meta-Analysis. Open Forum Infect. Dis. 2020, 7, ofaa005. [CrossRef]

8. Muller, L.M.; Gorter, K.J.; Hak, E.; Goudzwaard, W.L.; Schellevis, F.G.; Hoepelman, A.I.; Rutten, G.E. Increased risk of common infections in patients with type 1 and type 2 diabetes mellitus. Clin. Infect. Dis. 2005, 41, 281-288. [CrossRef] 
9. Papagianni, M.; Metallidis, S.; Tziomalos, K. Herpes zoster and diabetes mellitus: A review. Diabetes Ther. 2018, 9, 545-550. [CrossRef]

10. Heymann, A.D.; Chodick, G.; Karpati, T.; Kamer, L.; Kremer, E.; Green, M.S.; Kokia, E.; Shalev, V. Diabetes as a risk factor for herpes zoster infection: Results of a population-based study in Israel. Infection 2008, 36, 226-230. [CrossRef]

11. Kawai, K.; Yawn, B.P. Risk Factors for Herpes Zoster: A systematic review and meta-analysis. Mayo Clin. Proc. 2017, 92, 1806-1821. [CrossRef]

12. Suaya, J.A.; Chen, S.-Y.; Li, Q.; Burstin, S.J.; Levin, M.J. Incidence of herpes zoster and persistent post-zoster pain in adults with or without diabetes in the United States. Open Forum Infect. Dis. 2014, 1, ofu049. [CrossRef]

13. Saadatian-Elahi, M.; Bauduceau, B.; Del-Signore, C.; Vanhems, P. Diabetes as a risk factor for herpes zoster in adults: A synthetic literature review. Diabetes Res. Clin. Pract. 2020, 159, 107983. [CrossRef]

14. Tsai, M.S.; Lin, M.H.; Lee, C.P.; Yang, Y.H.; Chen, W.C.; Chang, G.H.; Tsai, Y.T.; Chen, P.C.; Tsai, Y.H. Chang gung research database: A multi-institutional database consisting of original medical records. Biomed. J. 2017, 40, 263-269. [CrossRef]

15. Shao, S.C.; Chan, Y.Y.; Kao Yang, Y.H.; Lin, S.J.; Hung, M.J.; Chien, R.N.; Lai, C.C.; Lai, E.C. The chang gung research database-A multi-institutional electronic medical records database for real-world epidemiological studies in Taiwan. Pharmacoepidemiol. Drug Saf. 2019, 28, 593-600. [CrossRef]

16. Diabetes Association of The Republic Of China. Executive summary of the DAROC clinical practice guidelines for diabetes care-2018. J. Formos Med. Assoc. 2020, 119, 577-586. [CrossRef]

17. Nagin, D.S.; Odgers, C.L. Group-based trajectory modeling in clinical research. Annu. Rev. Clin. Psychol. 2010, 6, 109-138. [CrossRef]

18. Rathmann, W.; Schwandt, A.; Hermann, J.M.; Kuss, O.; Roden, M.; Laubner, K.; Best, F.; Ebner, S.; Plaumann, M.; Holl, R.W.; et al Distinct trajectories of $\mathrm{HbA} 1 \mathrm{c}$ in newly diagnosed Type 2 diabetes from the DPV registry using a longitudinal group-based modelling approach. Diabet. Med. 2019, 36, 1468-1477. [CrossRef]

19. Elmer, J.; Jones, B.L.; Nagin, D.S. Using the Beta distribution in group-based trajectory models. BMC Med. Res. Methodol. 2018, 18, 152. [CrossRef]

20. Jones, B.L.; Nagin, D.S. Advances in Group-Based Trajectory Modeling and an SAS Procedure for Estimating Them. Sociol. Methods Res. 2007, 35, 542-571. [CrossRef]

21. Laiteerapong, N.; Karter, A.J.; Moffet, H.H.; Cooper, J.M.; Gibbons, R.D.; Liu, J.Y.; Gao, Y.; Huang, E.S. Ten-year hemoglobin A1c trajectories and outcomes in type 2 diabetes mellitus: The Diabetes \& Aging Study. J. Diabetes Complicat. 2017, 31, 94-100. [CrossRef]

22. Vossen, M.T.; Gent, M.R.; Weel, J.F.; de Jong, M.D.; van Lier, R.A.; Kuijpers, T.W. Development of virus-specific CD4+ T cells on reexposure to Varicella-Zoster virus. J. Infect. Dis. 2004, 190, 72-82. [CrossRef]

23. Pearson-Stuttard, J.; Blundell, S.; Harris, T.; Cook, D.G.; Critchley, J. Diabetes and infection: Assessing the association with glycaemic control in population-based studies. Lancet Diabetes Endocrinol. 2016, 4, 148-158. [CrossRef]

24. Martinez, P.J.; Mathews, C.; Actor, J.K.; Hwang, S.A.; Brown, E.L.; De Santiago, H.K.; Fisher Hoch, S.P.; McCormick, J.B.; Mirza, S Impaired CD4+ and T-helper 17 cell memory response to Streptococcus pneumoniae is associated with elevated glucose and percent glycated hemoglobin A1c in Mexican Americans with type 2 diabetes mellitus. Transl. Res. 2014, 163, 53-63. [CrossRef]

25. Restrepo, B.I.; Twahirwa, M.; Rahbar, M.H.; Schlesinger, L.S. Phagocytosis via complement or Fc-gamma receptors is compromised in monocytes from type 2 diabetes patients with chronic hyperglycemia. PLoS ONE 2014, 9, e92977. [CrossRef]

26. Stegenga, M.E.; van der Crabben, S.N.; Dessing, M.C.; Pater, J.M.; van den Pangaart, P.S.; de Vos, A.F.; Tanck, M.W.; Roos, D.; Sauerwein, H.P.; van der Poll, T. Effect of acute hyperglycaemia and/or hyperinsulinaemia on proinflammatory gene expression, cytokine production and neutrophil function in humans. Diabet. Med. 2008, 25, 157-164. [CrossRef]

27. Okamoto, S.; Hata, A.; Sadaoka, K.; Yamanishi, K.; Mori, Y. Comparison of varicella-zoster virus-specific immunity of patients with diabetes mellitus and healthy individuals. J. Infect. Dis. 2009, 200, 1606-1610. [CrossRef]

28. Critchley, J.A.; Carey, I.M.; Harris, T.; DeWilde, S.; Hosking, F.J.; Cook, D.G. Glycemic control and risk of infections among people with type 1 or type 2 diabetes in a large primary care cohort study. Diabetes Care 2018, 41, 2127-2135. [CrossRef]

29. Hine, J.L.; de Lusignan, S.; Burleigh, D.; Pathirannehelage, S.; McGovern, A.; Gatenby, P.; Jones, S.; Jiang, D.; Williams, J.; Elliot, A.J.; et al. Association between glycaemic control and common infections in people with Type 2 diabetes: A cohort study. Diabet. Med. 2017, 34, 551-557. [CrossRef] [PubMed]

30. Munoz-Quiles, C.; Lopez-Lacort, M.; Ampudia-Blasco, F.J.; Diez-Domingo, J. Risk and impact of herpes zoster on patients with diabetes: A population-based study, 2009-2014. Hum. Vaccines Immunother. 2017, 13, 2606-2611. [CrossRef] 